\title{
Methylene blue-assisted lymph node dissection technique is not associated with an increased detection of lymph node metastases in colorectal cancer
}

\author{
Bruno Märkl ${ }^{1}$, Tina Schaller ${ }^{1}$, Ines Krammer ${ }^{1}$, Claudio Cacchi ${ }^{1}$, Hans M Arnholdt ${ }^{1}$, \\ Gerhard Schenkirsch ${ }^{2}$, Hallie Kretsinger ${ }^{1}$, Matthias Anthuber ${ }^{3}$ and Hanno Spatz \\ ${ }^{1}$ Institute of Pathology, Klinikum Augsburg, Augsburg, Germany; ${ }^{2}$ Clinical and Population-Based Cancer \\ Registry of Augsburg, Klinikum Augsburg, Augsburg, Germany and ${ }^{3}$ Department of Visceral and \\ Transplantation Surgery, Klinikum Augsburg, Augsburg, Germany
}

\begin{abstract}
Lymph node staging is of paramount importance for prognosis estimation and therapy stratification in colorectal cancer. A high number of harvested lymph nodes is associated with an improved outcome. Methylene blue-assisted lymph node dissection effectively improves the lymph node harvest and ensures sufficient staging. Now, the effect on node positivity rate and stage-related outcome was investigated. The study cohort with advanced lymph node dissection consisted of 669 colorectal cancer cases of all stages, which were collected between 2007 and 2012. A historical collection of 663 cases investigated with conventional techniques between 2002 and 2004 served as control. Lymph node harvest was dramatically improved in the study group with mean lymph node numbers of $34 \pm 17$ vs $13 \pm 5(P<0.001)$ and sufficient staging rates of $98 \%$ vs $62 \%(P<0.001)$. However, neither the rate of nodal positive cases $(37 \%$ vs $37 \% ; P=0.98)$ nor the rate of $N 2$ cases differed between the two groups $(14 \%$ vs $13 \% ; P=0.80)$. Furthermore, no differences were found concerning the outcome in both groups. The advanced lymph node dissection technique guarantees adequate histopathological lymph node staging in virtually all cases of colorectal cancer and is therefore extremely helpful. The hypothesis that it also provides a higher sensitivity in detecting metastases, however, could be not proved.
\end{abstract}

Modern Pathology (2013) 26, 1246-1254; doi:10.1038/modpathol.2013.61; published online 19 April 2013

Keywords: colorectal cancer; lymph node; methylene blue

Histopathological lymph node staging remains the most important prognostic factor in colorectal cancer. ${ }^{1}$ In contrast to stage III cancers, the benefit of adjuvant chemotherapy is limited in stage II cases and, therefore, is offered only in defined risk situations. ${ }^{2,3}$ Insufficient lymph node harvest is one of these risk factors. A harvest of at least 12 nodes is required by the Union for International Cancer Control for adequate staging. ${ }^{4}$ However, many studies from different countries have shown that this standard is not achieved in daily practice. ${ }^{5-7}$ The harvest is especially negatively influenced by neoadjuvant radiochemotherapy in rectal cancer

Correspondence: Dr B Märkl, PD, Institute of Pathology, Klinikum Augsburg, Stenglinstrasse 2, 86156 Augsburg, Bavaria, Germany. E-mail: bruno.maerkl@klinikum-augsburg.de

Received 21 December 2012; revised 9 February 2013; accepted 9 February 2013; published online 19 April 2013 patients. $^{8,9}$ On the other hand, the threshold of 12 lymph nodes itself is debated controversially. ${ }^{10}$ The recommendations in the literature range from 9 to $>30$ lymph nodes that should be harvested per case. ${ }^{5,11-14}$ Several studies concordantly report an improved outcome with increasing lymph node numbers in stage II and III colon cancers. ${ }^{15}$ Missed lymph node metastases caused by improper investigation are thought to be the most probable explanation for this finding, which is also known as the Will Rogers phenomenon. ${ }^{16}$

The number of investigated lymph nodes, however, is important not only for prognosis estimation and therapy stratification, but also as a benchmark for surgical quality. ${ }^{17}$ Fat clearance is a well-known technique to improve lymph node harvest not only in colorectal cancer. ${ }^{18-22}$ However, all of these techniques are time consuming, expensive and need potentially toxic agents. In 2007 , we introduced the 
methylene blue-assisted lymph node dissection method as a cheap and simple alternative method to improve lymph node harvest in gastrointestinal cancers. ${ }^{23,24}$

The aim of this study was to investigate the effect of an advanced lymph node dissection technique dependent on different clinicopathological factors (age, location, T-stage, therapy, and so on) in a large study group compared with a historical control group of equal size. Moreover, we addressed the question of whether an improved yield is associated with an increase in the node positivity rate and therefore influences the stage-related outcome. In addition, we harvested the lymph nodes in a subgroup of cases in sequential portions to acquire data about the probability of detecting the first relevant lymph node beyond the threshold of 12 lymph nodes.

\section{Patients and methods}

\section{Study and Control Cohorts}

The study group consisted of 669 cases that were prospectively collected between 2007 and 2012 . A total of 110 cases were part of foregoing studies. In all cases, lymph nodes were dissected using special methods to optimize lymph node harvest and ensure sufficient staging.

A cohort of 663 historical cases investigated between 2002 and 2004 using conventional lymph node dissection techniques served as control. Inclusion criteria for both groups were histologically proven primary colorectal cancer and negative resection margins. An available follow-up longer than 2 months was necessary before the cases went into the survival analysis. All patients were treated in two hospitals that belong to the Klinikum Augsburg.

The study was approved by the internal review board of the Klinikum Augsburg.

\section{Advanced Lymph Node Dissection}

In 559 cases, the methylene blue-assisted lymph node dissection technique was the only applied method. The technique has been described before. $^{23,24}$ In brief, an ex vivo intra-arterial injection of $15-20 \mathrm{ml}$ of methylene blue solution is performed in the fresh or shortly formalin-fixed ( $\leq 4 \mathrm{~h}$ ) specimen. Lymph nodes were then dissected manually after fixing overnight.

In 55 cases, mesenteric fat clearance was performed after initial conventional dissection. In another 55 cases, the methylene blue-assisted lymph node dissection technique and fat clearance were combined. ${ }^{23,24}$

\section{Sequential Lymph Node Dissection}

Sequential lymph node dissection was performed in a subset of 94 cases. In these cases, the mesenteric fat of the specimens was divided into three parts: the tumor region, the proximal and the distal parts. The tumor region is defined as the complete fat under the tumor with a length of at least $6 \mathrm{~cm}$. After cutting out tissue samples for routine tumor diagnosis, lymph node dissection started in the tumor region. In the order of detection, lymph nodes of this region were bundled into four portions of different sizes (5-4-3-all remaining; Figure 1). Lymph nodes that appeared within the tumor slides were included in the first portion. Then, the lymph nodes of the proximal and distal parts were dissected and embedded.

\section{Clinical and Pathological Data}

The clinical data were obtained from the clinical and population-based cancer registry of Augsburg and from hospital records. The histopathological data were taken from pathology reports and are the results of routine examination of the specimens.

\section{Follow-Up and Statistics}

Follow-up data have been provided by the clinical and population-based cancer registry of Augsburg. The median follow-up time was calculated on the basis of the censored cases. Numeric values were compared using the $t$-test or the Mann-Whitney Rank-Sum test, depending on the results of the distribution test. For the comparison of three groups, the one-way RM ANOVA test was used. Dichotomous values were analyzed by the $\chi^{2}$-test or Fisher's exact test depending on the sample sizes. The Gehan-Breslow test was used to compare

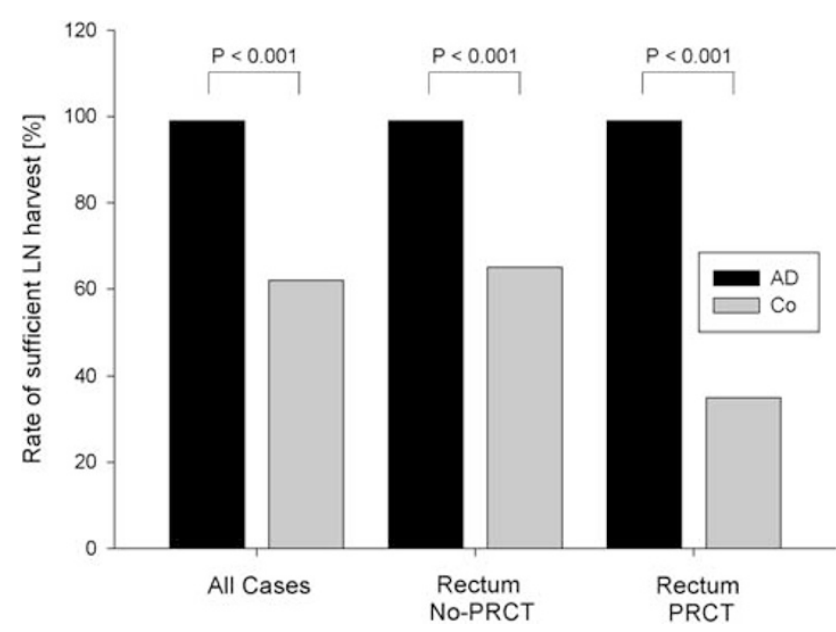

Figure 1 Rate of sufficient lymph node harvest same categories as in Figure 2. AD, advanced lymph node dissection technique; Co, control group; No-PRCT, no preoperative radiochemotherapy; PRCT, preoperative radiochemotherapy. 
outcome data. Mean values are given with \pm 1 s.d. A $P$-value $<0.05$ was considered significant. All statistical calculations were performed using the Sigma Plot 11.0 software package (Systat, Richmond, VA, USA).

\section{Results}

\section{Clinicopathological Data and Lymph Node Harvest}

The two groups were generally well balanced. There was, however, a trend toward a higher rate of neoadjuvant administration of radiochemotherapy in rectal cancer patients of the study group ( $47 \%$ vs $38 \% ; P=0.20$ ) and a highly significant lower rate of high-grade cancers in the study group (21\% vs $33 \%$; $P<0.001$; Table 1).

There was a highly significant improvement in lymph node harvest with the introduction of the methylene blue-assisted lymph node dissection technique in comparison with the conventional technique, with mean lymph node numbers of $34 \pm 17$ and $13 \pm 5(P<0.001)$, respectively. The rate of insufficient harvest decreased dramatically from $38 \%$ to $2 \%(P<0.001)$. This effect was even larger in cases of neoadjuvantly treated rectal cancers (65\% vs 1\%; $P<0.001$; Table 2; Figures 1 and 2).

\section{Rates of Lymph Node Positivity}

In contrast to the results of the lymph node harvest, there was no significant difference concerning the rate of lymph node positivity. The rates for the study and control groups were absolutely identical at $37 \%$ $(P=0.98)$. The only trends toward higher rates of lymph node metastases in the study group were detected in subgroups of high-grade cancers $(60 \% \mathrm{vs}$ $49 \% ; P=0.063)$ and rectal cancers without neoadjuvant therapy ( $48 \%$ vs $40 \%$; $P=0.0114$; Tables $1-3$ and Figure 3).

The rate of overall positivity and the rate of N2-cases ( $\geq 3$ positive lymph nodes) were identical in both groups with rates of $14 \%$ vs $13 \%(P=0.80)$ and a mean number of positive lymph nodes of $4 \pm 3$ and $4 \pm 4(P=0.78)$, respectively.

The occurrence of metastases is associated with a higher number of harvested lymph nodes in both groups. This effect, however, reaches high significance in the control group (mean: $13 \pm 5$ vs $14 \pm 5$; $P<0.001$ ), whereas it is only marginally significant in the study group (mean: $33 \pm 16$ vs $36 \pm 18$; $P=0.053$; Figure 4).

\section{Overall Survival}

As the study group was compared with a historical cohort, the median follow-up times differed highly significantly $(P<0.001)$. For the different subgroups of the study group they ranged between 22 and 26 months and for the control groups between 61 and 75 months.

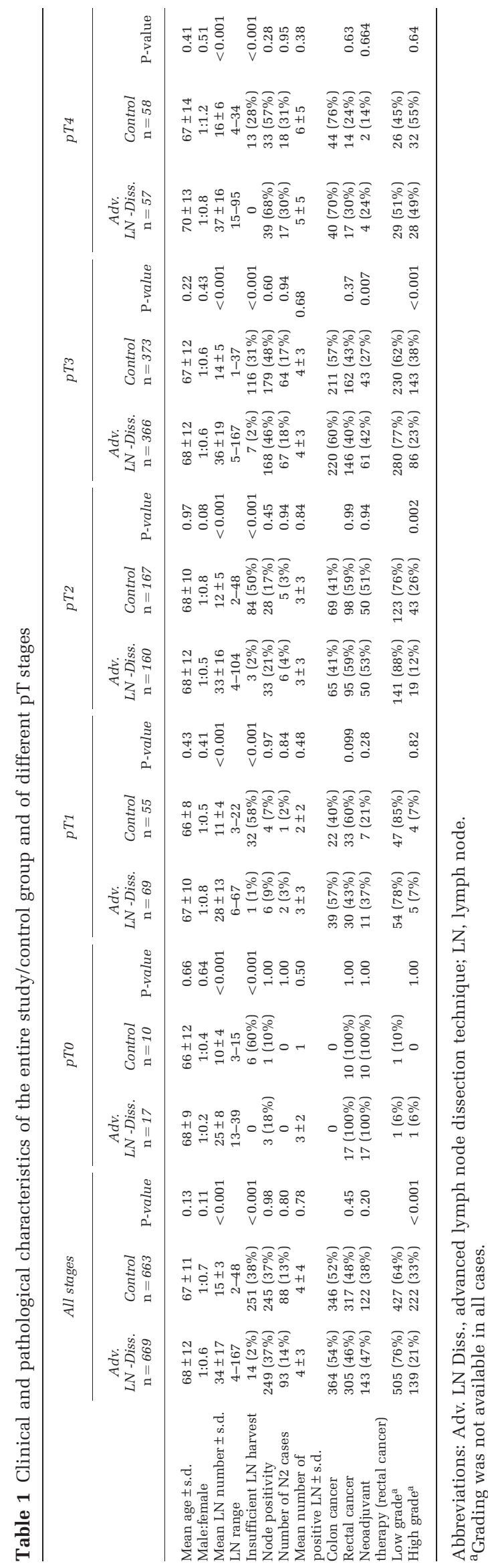


Table 2 Clinical and pathological characteristics of rectal cancers with and without preoperative radiochemotherapy

\begin{tabular}{|c|c|c|c|c|c|c|}
\hline & \multicolumn{3}{|c|}{ Preoperative treatment } & \multicolumn{3}{|c|}{ No preoperative treatment } \\
\hline & $\begin{array}{c}\text { Adv. LN -Diss. } \\
\mathrm{n}=137\end{array}$ & $\begin{array}{l}\text { Control } \\
\mathrm{n}=112\end{array}$ & $\mathrm{P}$-value & $\begin{array}{c}A d v . \text { LN -Diss. } \\
\mathrm{n}=168\end{array}$ & $\begin{array}{l}\text { Control } \\
\mathrm{n}=205\end{array}$ & $\mathrm{P}$-value \\
\hline Mean age \pm s.d. & $64 \pm 12$ & $64 \pm 10$ & 0.39 & $68 \pm 12$ & $68 \pm 11$ & 0.68 \\
\hline Male:female & $1: 0.3$ & $1: 0.5$ & 0.26 & $1: 0.6$ & $1: 0.6$ & 0.94 \\
\hline Mean LN number \pm s.d. & $28 \pm 10$ & $10 \pm 4$ & $<0.001$ & $35 \pm 16$ & $13 \pm 5$ & $<0.001$ \\
\hline LN range & $7-57$ & $3-20$ & & $10-86$ & $2-34$ & \\
\hline Insufficient LN harvest & $2(1 \%)$ & $73(65 \%)$ & $<0.001$ & $1(1 \%)$ & $76(37 \%)$ & $<0.001$ \\
\hline Node positivity & $36(26 \%)$ & $29(26 \%)$ & 0.939 & $81(48 \%)$ & $81(40 \%)$ & 0.114 \\
\hline Number of N2 cases & $15(11 \%)$ & $9(8 \%)$ & 0.58 & $32(19 \%)$ & $31(15 \%)$ & 0.39 \\
\hline Mean number of positive $L N \pm$ s.d. & $\begin{array}{c}4 \pm 4 \\
77(56 \%)\end{array}$ & $\begin{array}{c}4 \pm 3 \\
67(60 \%)\end{array}$ & 0.68 & $\begin{array}{c}4 \pm 4 \\
65(39 \%)\end{array}$ & $\begin{array}{c}4 \pm 4 \\
74(36 \%)\end{array}$ & 0.83 \\
\hline pT0-2 & $77(56 \%)$ & $67(60 \%)$ & & $65(39 \%)$ & $74(36 \%)$ & \\
\hline pT3-4 & $60(44 \%)$ & $45(40 \%)$ & 0.66 & $103(61 \%)$ & $131(64 \%)$ & 0.68 \\
\hline Low grade* & $97(71 \%)$ & $85(76 \%)$ & & $137(82 \%)$ & $148(72 \%)$ & \\
\hline High grade* & $25(18 \%)$ & $18(16 \%)$ & 0.69 & $29(17 \%)$ & $56(27 \%)$ & 0.032 \\
\hline
\end{tabular}

Abbreviations: Adv. LN Diss., advanced lymph node dissection technique; LN, lymph node.

*Note: grading was not available in pTo cases and after local resection.

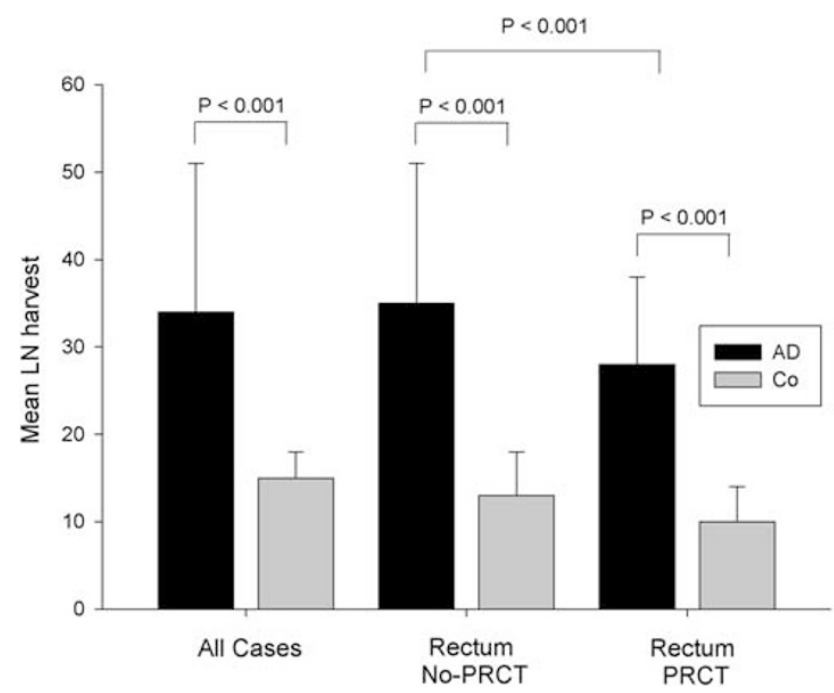

Figure 2 Mean lymph node harvest dependent on site and application of neoadjuvant therapy. Error bars represent 1 s.d. $\mathrm{AD}$, advanced lymph node dissection technique; Co, control group; No-PRCT, no preoperative radiochemotherapy; PRCT, preoperative radiochemotherapy.

The overall survival analysis showed highly significant outcome differences between nodal negative and positive cases. However, it did not reveal significant differences between advanced and conventional lymph node dissection. The KaplanMeier curves are given in Figures 5 and 6.

\section{Sequential Lymph Node Dissection}

The clinicopathological data of this subset of 94 patients are given in Table 4 . There was a $63 \%$ detection rate of the first positive lymph node among the first five dissected lymph nodes of the tumor region. The rates for portions II-IV were $23 \%$, $3 \%$ and $9 \%$, respectively (Figure 7 ). This means there was an $89 \%$ (31 out of 35 cases) chance of detecting a first lymph node metastasis among the first 12 lymph nodes. In three of the remaining four cases (one right hemicolon, two sigmoid colon and one rectal specimen), the first lymph node metastases were detected in portion IV. Only in one case was a lymph node metastasis found exclusively outside of the defined tumor region (Figure 8). This was a micrometastasis (pN1mi) in pT2, low-grade rectal cancer. The lymph node yield of these 4 cases ranged between 22 and 85 lymph nodes, the pT stages from T2 to T4. One case was a cancer located in the right colon, whereas the other three cases occurred in the left colon or rectum (Table 4). Out of 140 positive lymph nodes, 105 were located in the tumor region compared with 18 and 17 in the proximal and distal region, respectively $(P>0.001)$.

\section{Discussion}

There is still much debate on how many lymph nodes must be examined in colorectal cancer and how these numbers can be achieved in daily practice. For decades, fat clearance techniques have been the only approach to improve lymph node harvest in colorectal cancers. ${ }^{18-22}$ We recently introduced the methylene blue-assisted lymph node dissection technique as a simple, cheap and very effective alternative method. Moreover, the usefulness of this technique has been approved by several other groups. ${ }^{23-30}$ This study showed again that dramatic improvements are seen with the use of advanced lymph node dissection techniques (Figures 1 and 2). This was especially true in neoadjuvantly treated rectal cancer cases-a situation strongly associated with low lymph node counts. ${ }^{9}$ It must be emphasized that the study group consisted of 614 cases with the methylene blue-assisted lymph node dissection technique and 55 additional cases with the fat clearance technique. 
Table 3 Clinical and pathological characteristics of low- and high-grade cancers

\begin{tabular}{|c|c|c|c|c|c|c|}
\hline \multirow{2}{*}{ Parameter } & \multicolumn{3}{|c|}{ Low grade } & \multicolumn{3}{|c|}{ High grade } \\
\hline & $\begin{array}{c}A d v . L N-D i s s \\
\mathrm{n}=505\end{array}$ & $\begin{array}{l}\text { Control } \\
\mathrm{n}=427\end{array}$ & P-value & $\begin{array}{c}\text { Adv. LN -Diss. } \\
\mathrm{n}=139\end{array}$ & $\begin{array}{l}\text { Control } \\
n=222\end{array}$ & $\mathrm{P}$-value \\
\hline Mean age \pm s.d. & $68 \pm 12$ & $68 \pm 11$ & 0.27 & $68 \pm 12$ & $67 \pm 12$ & 0.36 \\
\hline Male:female & $1: 0.5$ & $1: 0.6$ & 0.20 & $1: 0.8$ & $1: 0.8$ & 0.96 \\
\hline Mean LN number \pm s.d. & $35 \pm 17$ & $13 \pm 5$ & $<0.001$ & $35 \pm 18$ & $14 \pm 5$ & $<0.001$ \\
\hline LN range & $4-129$ & $2-48$ & & $9-167$ & $1-34$ & \\
\hline Insufficient LN harvest & $13(3 \%)$ & $175(41 \%)$ & $<0.001$ & $1(1 \%)$ & $67(30 \%)$ & $<0.001$ \\
\hline Node positivity & $165(33 \%)$ & $136(32 \%)$ & 0.84 & $83(60 \%)$ & $109(49 \%)$ & 0.063 \\
\hline Number of N2 cases & $56(11 \%)$ & $37(9 \%)$ & 0.26 & $37(27 \%)$ & $51(23 \%)$ & 0.51 \\
\hline Mean number of positive $\mathrm{LN} \pm$ s.d. & $3 \pm 3$ & $3 \pm 3$ & 0.41 & $4 \pm 4$ & $5 \pm 4$ & 0.91 \\
\hline pT0-2 & $196(39 \%)$ & $171(40 \%)$ & & $25(18 \%)$ & $47(21 \%)$ & \\
\hline pT3-4 & $309(61 \%)$ & $256(60 \%)$ & 0.80 & $114(82 \%)$ & $175(79 \%)$ & 0.55 \\
\hline Colon cancer & $272(54 \%)$ & $192(45 \%)$ & & $86(62 \%)$ & $148(67 \%)$ & \\
\hline Rectal cancer & $233(46 \%)$ & $235(55 \%)$ & 0.008 & $53(38 \%)$ & $74(33 \%)$ & 0.42 \\
\hline Neoadjuvant therapy (rectal cancer) & $100(43 \%)$ & $88(37 \%)$ & 0.27 & $27(51 \%)$ & $19(26 \%)$ & 0.06 \\
\hline
\end{tabular}

Abbreviations: Adv. LN Diss., advanced lymph node dissection technique; LN, lymph node.

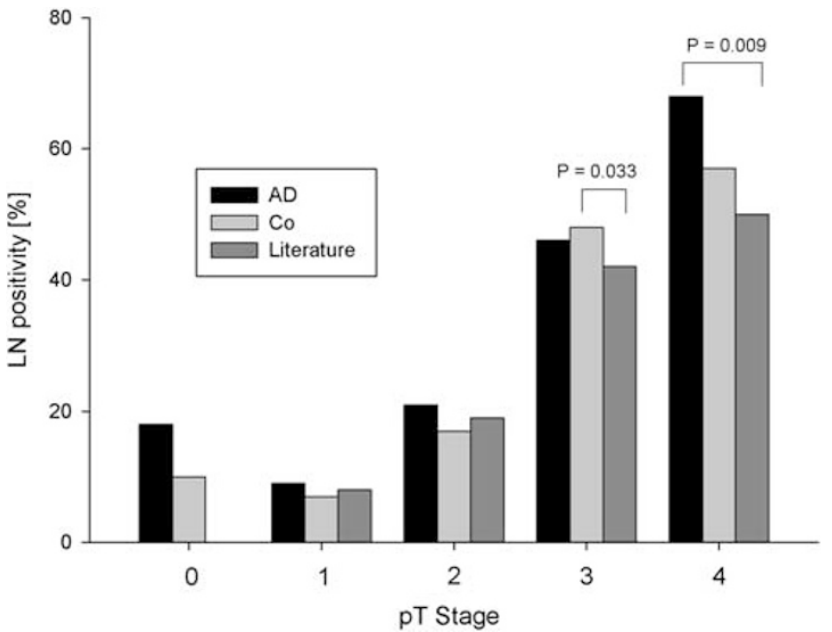

Figure 3 Rates of lymph node positivity dependent on pT stage in percentages. The study and the control groups are compared with data from the literature. ${ }^{34}$

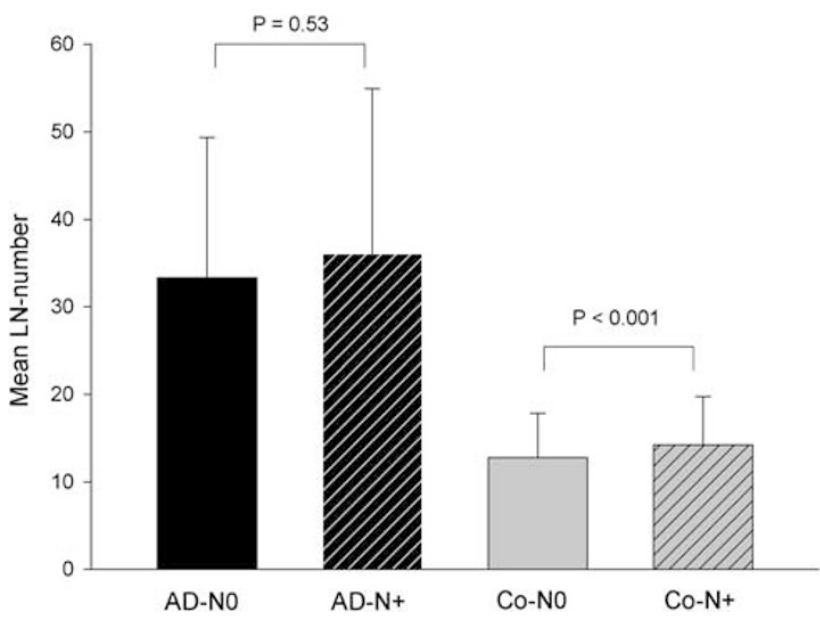

Figure 4 Mean lymph node harvest dependent on nodal status.

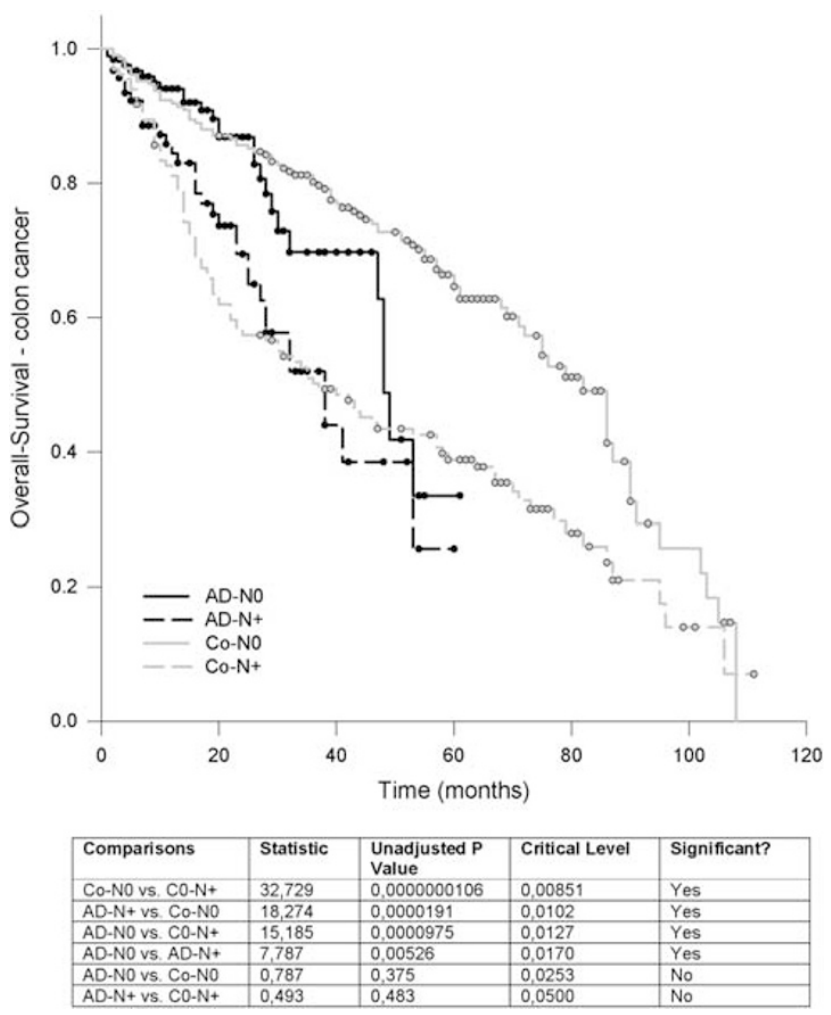

Figure 5 Kaplan-Meier curve of overall survival in colon cancers with highly significant worse outcome in nodal positive cases compared with nodal negative cancers. No survival differences between the study and the control group.

To evaluate as many lymph nodes as possible per specimen seems especially important because of the well-known positive association between the number of dissected lymph nodes and patient outcome mainly in colon, but recently also in rectal, cancers. ${ }^{15,31}$ Insufficient surgery, neoadjuvant therapy and a stage migration effect (the so-called Will Rogers phenomenon) are considered to be the 


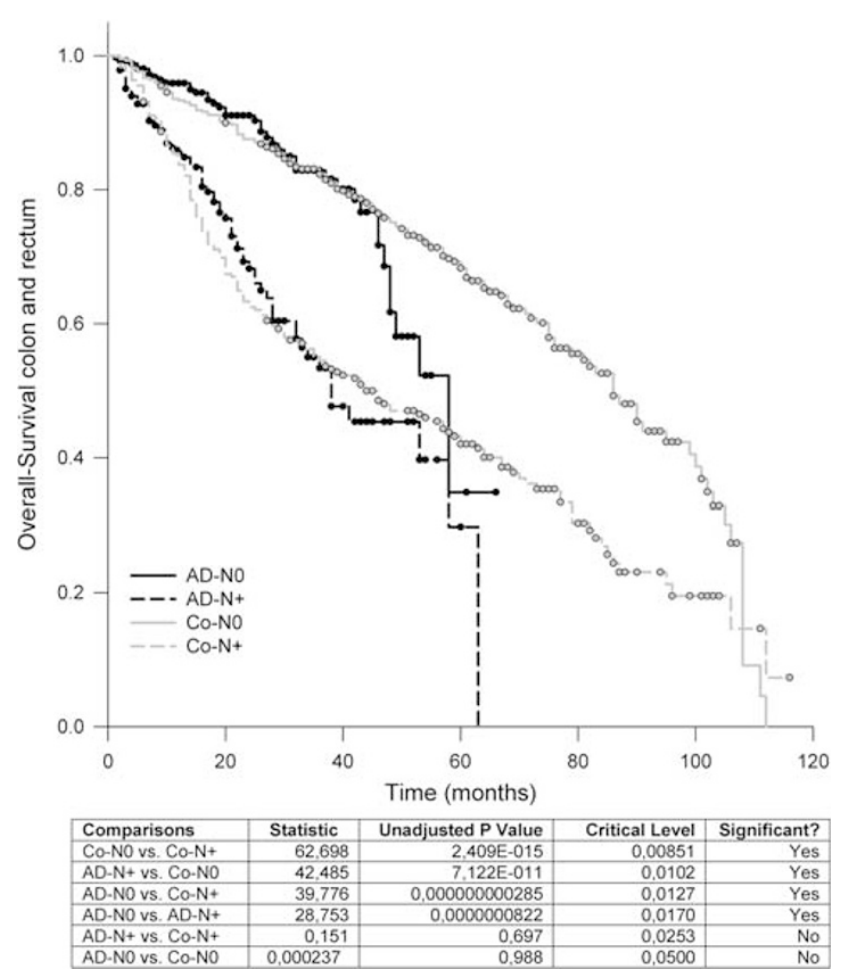

Figure 6 Same as in Figure 5 for colon and rectal cancers.

Table 4 Clinical and pathological characteristics of all and nodal positive cases of the sequential dissection

\begin{tabular}{lccc}
\hline Parameter & $\begin{array}{c}\text { Sequential } \\
\text { dissection } \\
\mathrm{n}=94\end{array}$ & $\begin{array}{c}\text { Nodal } \\
\text { positive cases } \\
\mathrm{n}=35\end{array}$ & $\begin{array}{c}\text { 1st Meta after } \\
\text { 12 LN } \mathrm{n}=4\end{array}$ \\
\hline Age & $69 \pm 12$ & $70 \pm 9$ & $73 \pm 10$ \\
Male:female & $1: 0.5$ & $1: 0.5$ & $1: 0.3$ \\
Mean LN \pm s.d. & $33 \pm 13$ & $36 \pm 15$ & $40 \pm 30$ \\
LN positivity & $35(37 \%)$ & & \\
pT0-2 & $42(45 \%)$ & $8(23 \%)$ & $1(25 \%)$ \\
pT3-4 & $52(55 \%)$ & $27(77 \%)$ & $3(75 \%)$ \\
Colon cancer & $59(63 \%)$ & $20(57 \%)$ & $3(75 \%)$ \\
Rectal cancer & $35(37 \%)$ & $15(43 \%)$ & $1(25 \%)$ \\
Neoadjuvant & $18(51 \%)$ & $8(53 \%)$ & 0 \\
therapy (rectal & & & \\
cancer) & $71(76 \%)$ & $23(66 \%)$ & $3(75 \%)$ \\
Low grade & $19(20 \%)$ & $12(34 \%)$ & $1(25 \%)$ \\
High grade $^{\mathrm{a}}$ & & &
\end{tabular}

Abbreviation: LN, lymph node.

The right column shows the characteristics of cases where the first lymph node metastasis did not occur among the first 12 dissected lymph nodes.

${ }^{\mathrm{a}}$ Grading was not available in all cases.

most likely explanations for this association. ${ }^{8,16}$ It seems very clear that a poor lymph node harvest is a risk factor for missing positive lymph nodes. Incorrect stage classification and withholding patients from adjuvant therapy are the negative consequences. Along with others, we reported upstaging after secondary lymph node dissection only in single or few cases. ${ }^{18,23,24}$

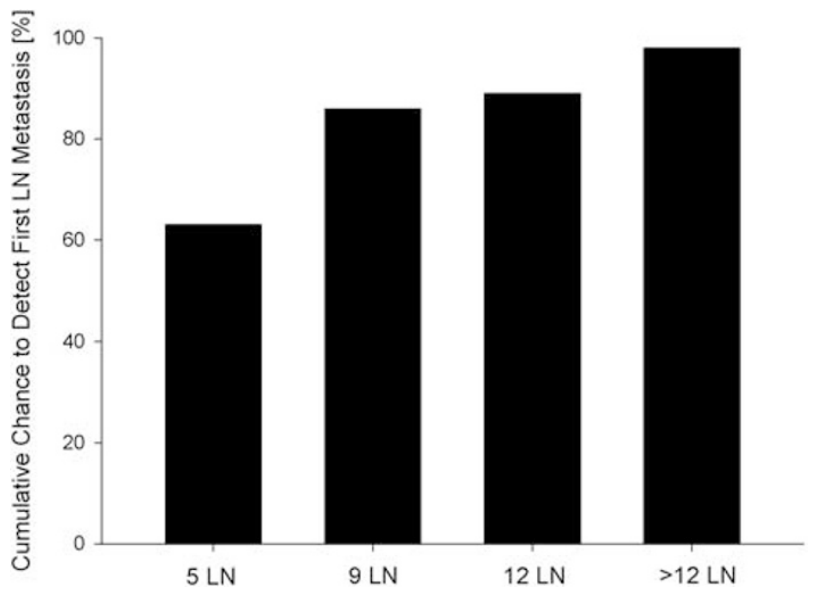

Figure 7 Cumulative chance in percentages to detect a first metastasis dependent on the number of harvested lymph nodes. LN, lymph nodes.

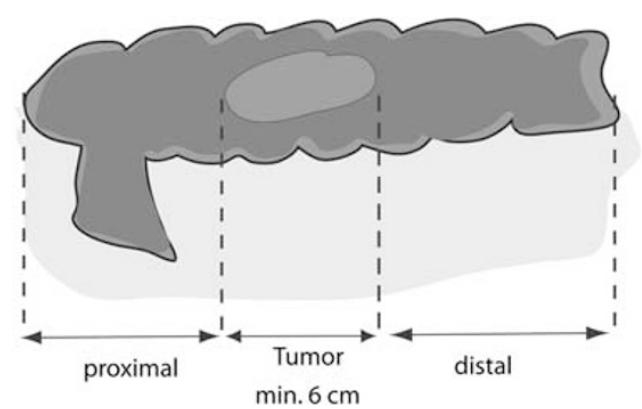

Figure 8 Schematic illustration of the three dissection parts. The tumor region included the fat below the entire tumor but measured at least $6 \mathrm{~cm}$. The first lymph node portions $(5-4-3-$ remaining lymph nodes) were dissected out of this region. The lymph nodes of the proximal and distal portions have been embedded separately.

Therefore, we expected statistical evidence for an improved accuracy of staging because of an improved lymph node harvest. However, the analysis of our data revealed no statistically different rates of lymph node positivity or $\mathrm{pN} 2$ cases between the study group and the historical group. Moreover, there was no trend toward higher metastasis detection after advanced dissection except in high-grade tumors and rectal cancers without neoadjuvant treatment. Are these two subgroups the ones that are likely to benefit from an improved lymph node yield? This seems questionable at least for highgrade cancers. The rate of high-grade cancers differed considerably between the two groups. We believe that a more restrictive diagnosis of highgrade cancers in the study group could be a very likely explanation for this difference. The highgrade cohort of the study group would therefore consist of particularly severe cases, resulting in an extraordinarily high lymph node metastasis rate of $60 \%$. The situation in rectal cancers is more difficult to interpret. One possible bias could be that surgery of liver metastases dramatically increased at our 
hospital within the time gap between the collection periods of the two groups. A consequence could be that more cases with primary metastases that usually receive no neoadjuvant therapy were admitted to our hospital. On the other hand, it cannot be completely excluded that these trends reflect real effects, although we rather would expect advantages in cases of early cancers or situations where lymph node dissection is difficult (eg, neoadjuvant therapy). Jepsen et $a l^{28}$ found an advantage in exactly such a subgroup. They reported an upstaging in pT1-2 cancers in a study with a design similar to ours. ${ }^{28}$ The reason for the discrepancy to our results can probably be found in the relatively low node positivity rate of their historical control group of only $9 \%$.

Brown et $a l^{32}$ and Kim et $a l^{33}$ performed complete embedding of residual mesenteric fat after careful primary manual dissection in colon and colorectal cancers in 15 and 48 cases, respectively. Only Brown et al showed an upstaging from No to N1 in one case. This, however, was probably not a true lymph node metastasis but a free deposit.

By comparing our data with the detailed analysis of Ricciardi et $a l^{34}$, which included $>120000$ cases, one can find an astonishing concordance (Figure 5). The overall lymph node positivity rate of $35 \%$ in their study was only slightly lower than the positivity rate of $37 \%$ in our study $(P=0.152)$. Only in pT4 cancers was a significantly higher rate of metastasis found in our study group when compared with the data of Ricciardi. The results for rectal cancers are also very similar with a nodal positive rate of $37 \%$ vs $38 \%$. This seems even more surprising because the rate of insufficient lymph node harvest in Ricciardi's cohort was considerably higher-61\% vs $2 \%$ and $38 \%$ in our study group and control group, respectively. In other words, the poor lymph node harvest did not cause significantly lower metastasis discovery. Despite an improved lymph node harvest over time, Porter et al ${ }^{35}$ could identify neither an increase in node positivity nor a change in outcome in population-based study. Recently, Parsons et al ${ }^{36}$ also found in their SEER database study an clearly improved lymph node harvest over time but no increase in lymph node positivity. Nevertheless, they confirmed again an association between lymph node retrieval and outcome. Analyzing the improvement of three hospitals concerning lymph node retrieval, Storli et $a l^{37}$ also could not show an upstaging from stages II to III. It seems that pathologists are very effective in detecting lymph node metastases. The results of sequential lymph node preparation point in the same direction (Figure 7). In $86 \%$ of the cases, the first lymph node metastasis was found among the first nine detected lymph nodes in close proximity to the tumor. In a recently published study, ${ }^{38}$ we performed detailed morphometric analyses of lymph nodes in colon cancer. We found that $49.5 \%$ of the metastasized lymph nodes were small $(\leq 5 \mathrm{~mm})$ but not minute $(\leq 1 \mathrm{~mm})$. In only 2 out of 81 cases, the largest positive lymph node measured $<4 \mathrm{~mm}$. In all other cases, the largest lymph node was large enough that it could hardly be missed during routine dissection. This could explain why pathologists in general show a poor performance in finding a high number of lymph nodes in colorectal cancer but are much more effective in detecting the crucial ones.

As a result of the reported strong correlation between lymph node harvest and outcome, and the considerable difference in mean lymph node number between the study and control group, we consequently expected a corresponding survival difference. However, this was not detectable. The Kaplan-Meier curves of the two cohorts are absolutely similar (Figures 5 and 6). The survival analysis is clearly hampered by the design of this study because the two groups have considerably different follow-up times. Nevertheless, the well-known effect of nodal status is documented very well by the analysis, indicating that at least stronger effects were detectable.

These results raise doubts about the correctness of the stage migration hypothesis as an explanation for the survival benefit of patients with many investigated lymph nodes. Wong et $a l^{39}$ compared the outcome of a total of 30365 patients among hospitals with different performances concerning lymph node harvest in colon cancers. The mean lymph node counts ranged between 5.9 and 14.9. Although they could identify a better outcome at the patient level in cases with at least 12 investigated lymph nodes, they could not find any survival differences between cases treated at the different hospitals. Moreover, there was also no difference concerning the node positivity rate among the hospitals (range: $28.1 \%$ to $31.7 \%$ ). Simunovic and Baxter $^{40}$ supposed that an unknown confounder might be the true explanation for the association between lymph node count and survival. Our morphometry analysis ${ }^{38}$ proved that the outcome in stage I/II colon cancer is influenced by lymph node size. Enlarged lymph nodes are easy to detect and, therefore, are associated with high lymph node counts. They are probably the morphological correlate of an enhanced immunoreaction responsible for an improved outcome.

As our study failed to show a higher sensitivity in metastasis detection, the use of advanced lymph node dissection techniques does not seem to be mandatory in colorectal cancer. Nevertheless, we recommend the methylene blue-assisted lymph node dissection technique because it ensures a sufficient lymph node harvest in virtually all cases, including neoadjuvantly treated rectal cancer. In addition, it is very cheap and fast. Insufficient lymph node harvest, on the other hand, places blame on the surgeon for performing an incomplete resection. Moreover, it is an indication for expensive chemotherapy with known side effects. 


\section{Acknowledgements}

We are grateful to Claudia Herbst for her excellent technical assistance. We further thank Barbara Kresse and Kai-Uwe Hebick for their help with data collection.

\section{Disclosure/conflict of interest}

The authors declare no conflict of interest.

\section{References}

1 Compton CC. Colorectal carcinoma: diagnostic, prognostic, and molecular features. Mod Pathol 2003;16: 376-388.

2 Figueredo A, Coombes ME, Mukherjee S. Adjuvant therapy for completely resected stage ii colon cancer. Cochrane Database Syst Rev 2008;16:CD005390.

3 Gill S, Loprinzi CL, Sargent DJ, et al. Pooled analysis of fluorouracil-based adjuvant therapy for stage ii and iii colon cancer: who benefits and by how much? J Clin Oncol 2004;22:1797-1806.

4 Sobin LH, Wittekind C. Tnm classification of malignant tumors, In: Sobin LH, Wittekind C (eds). TNM Classification of Malignant Tumors, 6th edn Vol., John Wiley \& Sons: Hoboken; 2002, pp 72-76.

5 Mainprize KS, Kulacoglu H, Hewavisinthe J, et al. How many lymph nodes to stage colorectal carcinoma? J Clin Pathol 1998;51:165-166.

6 Baxter NN, Virnig DJ, Rothenberger DA, et al. Lymph nodeevaluation in colorectal cancer patients: a population-based study. J Natl Cancer Inst 2005;97:219-225.

7 Cserni G. Lymph nodeharvest reporting in patients with carcinoma of the large bowel: a french population-based study. Cancer 1999;85:243-245.

8 Mekenkamp LJ, van Krieken JH, Marijnen CA, et al. Lymph noderetrieval in rectal cancer is dependent on many factors-the role of the tumor, the patient, the surgeon, the radiotherapist, and the pathologist. Am J Surg Pathol 2009;33:1547-1553.

9 Miller ED, Robb BW, Cummings OW, et al. The effects of preoperative chemoradiotherapy on lymph node sampling in rectal cancer. Dis Colon Rectum 2012;55: 1002-1007.

10 Govindarajan A, Gonen M, Weiser MR, et al. Challenging the feasibility and clinical significance of current guidelines on lymph node examination in rectal cancer in the era of neoadjuvant therapy. J Clin Oncol 2011;29:4568-4573.

11 Cianchi F, Palomba A, Boddi V, et al. Lymph noderecovery from colorectal tumor specimens: recommendation for a minimum number of lymph nodes to be examined. World J Surg 2002;26:384-389.

12 Goldstein NS. Lymph noderecoveries from 2427 pt3 colorectal resection specimens spanning 45 years: recommendations for a minimum number of recovered lymph nodes based on predictive probabilities. Am J Surg Pathol 2002;26:179-189.

13 Leibl S, Tsybrovskyy O, Denk H. How many lymph nodes are necessary to stage early and advanced adenocarcinoma of the sigmoid colon and upper rectum? Virchows Arch 2003;443:133-138.
14 Yoshimatsu K, Ishibashi K, Umehara A, et al. How many lymph nodes should be examined in dukes' b colorectal cancer? Determination on the basis of cumulative survival rate. Hepatogastroenterology 2005;52:1703-1706.

15 Chang GJ, Rodriguez-Bigas MA, Skibber JM, et al. Lymph nodeevaluation and survival after curative resection of colon cancer: systematic review. J Natl Cancer Inst 2007;99:433-441.

16 Feinstein AR, Sosin DM, Wells CK. The will rogers phenomenon. Stage migration and new diagnostic techniques as a source of misleading statistics for survival in cancer. N Engl J Med 1985;312:1604-1608.

17 Smith AJ, Driman DK, Spithoff K, et al. Guideline for optimization of colorectal cancer surgery and pathology. J Surg Oncol 2010;101:5-12.

18 Scott KW, Grace RH. Detection of lymph node metastases in colorectal carcinoma before and after fat clearance. Br J Surg 1989;76:1165-1167.

19 Gehoff A, Basten O, Sprenger T, et al. Optimal lymph nodeharvest in rectal cancer (uicc stages ii and iii) after preoperative 5-fu-based radiochemotherapy. Acetone compression is a new and highly efficient method. Am J Surg Pathol 2012;36:202-213.

20 Hernanz F, Garcia-Somacarrera E, Fernandez F. The assessment of lymph nodes missed in mesenteric tissue after standard dissection of colorectal cancer specimens. Colorectal Dis 2010;12:e57-e60.

21 Richter D, Lorenz D, Isemer FE, et al. [Acetone treatment of lymph node preparations in staging colorectal specimens]. Pathologe 2007;28:269-272.

22 Prabhudesai AG, Dalton R, Kumar D, et al. Mechanised one-day fat clearance method to increase the lymph node yield in rectal cancer specimens. Brit J Biomed Sci 2005;62:120-123.

23 Kerwel TG, Spatz J, Anthuber M, et al. Injecting methylene blue into the inferior mesenteric artery assures an adequate lymph node harvest and eliminates pathologist variability in nodal staging for rectal cancer. Dis Colon Rectum 2009;52:935-941.

24 Märkl B, Kerwel TG, Jähnig HG, et al. Methylene blueassisted lymph nodedissection in colon specimens: a prospective, randomized study. Am J Clin Pathol 2008;130:913-919.

25 Märkl B, Kerwel TG, Wagner T, et al. Methylene blue injection into the rectal artery as a simple method to improve lymph node harvest in rectal cancer. Mod Pathol 2007;20:797-801.

26 Martijnse IS, Dudink RL, Kusters M, et al. Patent blue staining as a method to improve lymph node detection in rectal cancer following neoadjuvant treatment. Eur J Surg Oncol 2012;38:252-258.

27 Klepsyte E, Samalavicius NE. Injection of methylene blue solution into the inferior mesenteric artery of resected rectal specimens for rectal cancer as a method for increasing the lymph node harvest. Tech Coloproctol 2012;16:207-211.

28 Jepsen RK, Ingeholm P, Lund EL. Upstaging of early colorectal cancers following improved lymph node yield after methylene blue injection. Histopathology 2012;61:788-794.

29 Frasson M, Faus C, Garcia-Granero A, et al. Pathological evaluation of mesocolic resection quality and ex vivo methylene blue injection: what is the impact on lymph nodeharvest after colon resection for cancer? Dis Colon Rectum 2012;55: 197-204. 
30 Törnroos A, Shabo I, Druvefors B, et al. Postoperative intra-arterial methylene blue injection of colorectal cancer specimens increases the number of lymph nodes recovered. Histopathology 2011;58:408-413.

31 Kidner TB, Ozao-Choy JJ, Yoon J, et al. Should quality measures for lymph nodedissection in colon cancer be extrapolated to rectal cancer? Am J Surg 2012;204: 843-847.

32 Brown HG, Luckasevic TM, Medich DS, et al. Efficacy of manual dissection of lymph nodes in colon cancer resections. Mod Pathol 2004;17:402-406.

33 Kim YM, Suh JH, Cha HJ, et al. Additional lymph nodeexamination from entire submission of residual mesenteric tissue in colorectal cancer specimens may not add clinical and pathologic relevance. Hum Pathol 2007;38:762-767.

34 Ricciardi R, Madoff RD, Rothenberger DA, et al. Population-based analyses of lymph node metastases in colorectal cancer. Clin Gastroenterol Hepatol 2006;4:1522-1527.
35 Porter GA, Urquhart $\mathrm{R}, \mathrm{Bu} \mathrm{J}$, et al. Improving nodal harvest in colorectal cancer: so what? Ann Surg Oncol 2012;19:1066-1073.

36 Parsons HM, Tuttle TM, Kuntz KM, et al. Association between lymph nodeevaluation for colon cancer and node positivity over the past 20 years. JAMA 2011;306: 1089-1097.

37 Storli K, Sondenaa K, Furnes B, et al. Improved lymph node harvest from resected colon cancer specimens did not cause upstaging from tnm stage ii to iii. World J Surg 2011;35:2796-2803.

38 Märkl B, Rössle J, Arnholdt HM, et al. The clinical significance of lymph node size in colon cancer. Mod Pathol 2012;25:1413-1422.

39 Wong SL, Ji H, Hollenbeck BK, et al. Hospital lymph node examination rates and survival after resection for colon cancer. JAMA 2007;298:2149-2154.

40 Simunovic M, Baxter NN. Lymph nodecounts in colon cancer surgery: lessons for users of quality indicators. JAMA 2007;298:2194-2195. 